\title{
Design, Development and Characterization of Valsartan Microsponges by Quasi Emulsion Technique and the Impact of Stirring Rate on Microsponge Formation
}

\author{
Madhuri Desavathu*, Raghuveer Pathuri, Mounika Chunduru \\ Department of Pharmaceutics, University College of Pharmaceutical sciences, Acharya Nagarjuna University, Guntur, India.
}

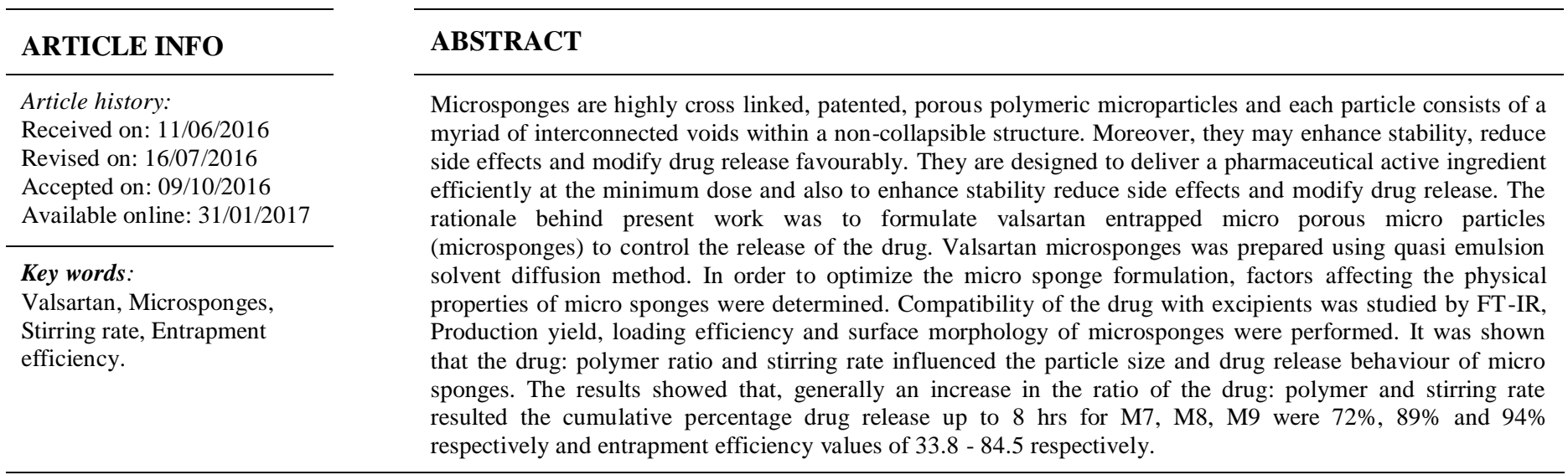

\section{INTRODUCTION}

Microsponges are polymeric delivery system. They are highly cross linked, porous polymeric microparticles which contain countless interconnected voids within a non-collapsible structure (D'souza et al., 2014) They are usually between 20 and 200 microns in diameter that acquire the flexibility to entrap a wide variety of active ingredients such as emollients, fragrances, sunscreens, essential oils, anti-infective, antifungal and antiinflammatory agents etc., that are mostly used for prolonged topical administration (Jain et al., 2011). Recently their use is also being investigated for oral drug delivery. In oral applications, the microsponge system has been shown to increase the rate of solubilisation of poorly water soluble drugs by

* Corresponding Author

Email:madhuridesavathu@gmail.com entrapping such drugs in the microsponge system's pores. As these pores are very small, the drug is in effect reduced to microscopic particles and the significant increase in the surface area thus greatly increases the rate of solubilisation (Karthika et al., 2013). Polymers are important in the field of drug delivery for their use as binders, viscosity, flow controlling, film coatings, to modify drug release characteristics. Controlled drug delivery systems include the maintenance of drug levels, administrations, increased patient compliance (Parikh et al., 2010).

The development of valsartan microsponge formulation of a drug is to enhance its therapeutic benefits and minimize its side effects, while improving the management of the disease condition. Valsartan is anti hypertensive drug belongs to BCS class II which is poorly soluble in water. In our present work Valsartan microsponges were prepared by quasi emulsion solvent diffusion technique with different stirring rates. 


\section{MATERIALS AND METHODS}

\section{Materials}

Valsartan as an endowment sample from Lobachemie Pvt. Ltd., Mumbai, Dichloromethane was procured from Merck specialities Pvt. Ltd., Mumbai, Ethyl cellulose and Polyvinyl alcohol also procured from Merck specialities Pvt. Ltd., Mumbai and Distilled water. All the reagent and materials were of analytical or pharmacopoeial grade.

\section{Methods for preparation of Valsartan microsponges}

The microsponges enclosing valsartan were fabricated by quasi-emulsion solvent diffusion method which is seemed to be promising for the preparation of valsartan microsponges as it is easy, reproducible, rapid and has the advantage of avoiding solvent toxicity. In the present study, dichloromethane (DCM), which is capable of dissolving both the drug and the polymer, was selected as the internal solvent and inner phase comprises of Ethyl cellulose (as mentioned in table 1) dissolved in $20 \mathrm{ml}$ of dichloromethane. Further valsartan was put in and dissolved through ultrasonication at $35{ }^{\circ} \mathrm{C}$ for $15 \mathrm{~min}$. Followed by dropwise addition of this mixture into aqueous solution of PVA (outer phase) with different stirring rates 1000, 1500, $2000 \mathrm{rpm}$ for 120 min. Subsequently, microsponges were formed due to dichloromethane removal from system by evaporation (Singh and vikas., 2010) Prepared microsponges were then filtered, washed with distilled water and subjected to drying at $40{ }^{\circ} \mathrm{C}$ for $24 \mathrm{~h}$ in hot air oven. Lastly microsponges obtained were weighed to determine production yield. Various formulation batches were prepared as per Table 1.

Table 1: Formulation of valsartan microsponges prepared by Quasi Emulsion Solvent diffusion technique.

\begin{tabular}{|c|c|c|c|c|c|c|c|}
\hline 音 & 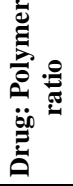 & 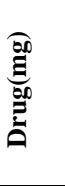 & $\underbrace{\text { Ox }}_{\text {Ex }}$ & 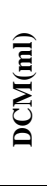 & 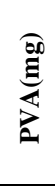 & 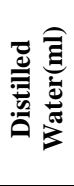 & 包 \\
\hline F1 & $1: 4$ & 100 & 400 & 20 & 400 & 150 & 1000 \\
\hline $\mathrm{F} 2$ & $1: 4$ & 100 & 400 & 20 & 400 & 150 & 1500 \\
\hline F3 & $1: 4$ & 100 & 400 & 20 & 400 & 150 & 2000 \\
\hline F4 & $1: 5$ & 100 & 500 & 20 & 500 & 150 & 1000 \\
\hline F5 & $1: 5$ & 100 & 500 & 20 & 500 & 150 & 1500 \\
\hline F6 & $1: 5$ & 100 & 500 & 20 & 500 & 150 & 2000 \\
\hline F7 & $1: 6$ & 100 & 600 & 20 & 600 & 150 & 1000 \\
\hline F8 & $1: 6$ & 100 & 600 & 20 & 600 & 150 & 1500 \\
\hline F9 & $1: 6$ & 100 & 600 & 20 & 600 & 150 & 2000 \\
\hline
\end{tabular}

* DMC-Dichloromethane.

* EC- Ethyl cellulose.

* PVA- Polyvinyl alcohol.

\section{CHARACTERIZATION OF PREPARED MICROSPONGES}

\section{Fourier transform infrared analysis}

The Physicochemical interaction between valsartan and ethyl cellulose polymer and polyvinyl alcohol used in the research were carried out by subjecting to IR spectral studies using Fourier Transform infrared Spectroscopy (Chadawar and Shaji, 2007). The samples were prepared by mixing the $100 \mathrm{mg}$ of the drug with 100 $\mathrm{mg}$ of polymer used in the preparation of the microsponges. These samples were scanned under diffuse reflectance mold and plotted the graph by $\mathrm{KBr}$ pellet method (Amrutiya et al., 2007). The spectra obtained for pure drug was compared with that of the physical mixtures of the drug with polymer and shown in figure 1 , 2 and 3.

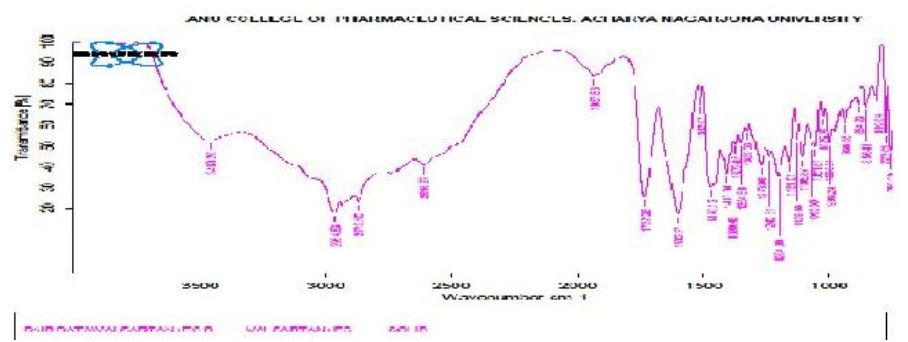

Fig. 1: IR spectra of pure valsartan.

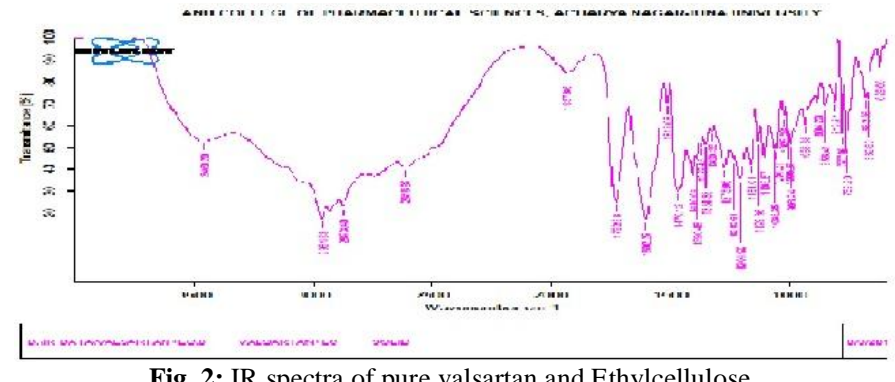

Fig. 2: IR spectra of pure valsartan and Ethylcellulose.

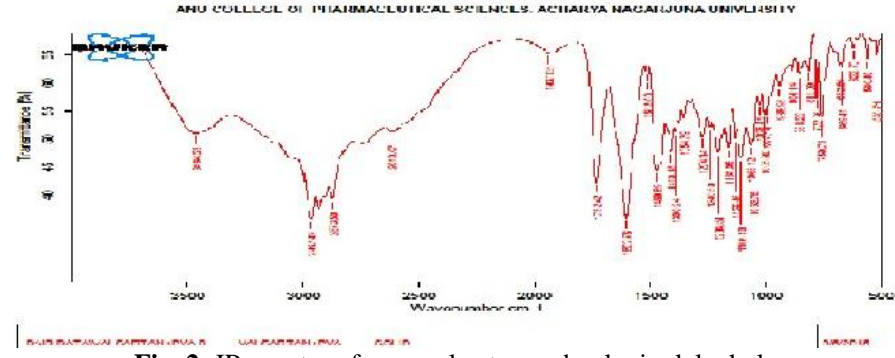

Fig. 2: IR spectra of pure valsartan and polyvinylalcohol.

\section{Particle Size Analysis}

Particle size and size distribution of microsponge particles was determined using optical microscope (Subhash et al., 2009). A minute quantity of microsponges was spread on a clean glass slide and average size of 100 microsponges was determined in each batch. The values were given in Table 2 for the formulations in the form of mean particle size.

\section{Determination of the production yield:}

The Microsponge production yield of valsartan was determined by calculating accurately the initial weight of the raw materials and the last weight of the microsponges (Mahajan et al., 2011). Obtained values were given in Table 2.

Production yield $=$ Production mass of microsponge $\times 100$

Theoretical mass (Drug + Polymer) 
Table 2: Production yield, actual drug content, Entrapment efficiency, and mean particle size of various microsponge formulations.

\begin{tabular}{ccccccc}
\hline S .No & Formulation code & Production yield $\pm *$ SD & $\begin{array}{c}\text { \% Drug } \\
\text { content } \pm * \text { SD }\end{array}$ & $\begin{array}{c}\text { \% Drug } \\
\text { release } \pm \text { SD }\end{array}$ & Particle size $\pm *$ SD & $\begin{array}{c}\text { Entrapment } \\
\text { efficiency } \pm * \text { SD }\end{array}$ \\
\hline 1 & F1 & $51.3 \pm 0.05$ & $33.7 \pm 0.65$ & $12.70 \pm 1.05$ & $83.2 \pm 0.08$ & $33.8 \pm 0.85$ \\
2 & F2 & $58.6 \pm 0.08$ & $42.6 \pm 0.93$ & $23.66 \pm 0.11$ & $79.3 \pm 0.93$ & $42.7 \pm 0.38$ \\
3 & F3 & $61.3 \pm 0.38$ & $51.4 \pm 0.92$ & $28.50 \pm 0.93$ & $65.2 \pm 0.75$ & $51.5 \pm 0.92$ \\
4 & F4 & $68.3 \pm 0.75$ & $45.3 \pm 0.49$ & $29.40 \pm 0.66$ & $61.6 \pm 0.92$ & $45.4 \pm 0.38$ \\
5 & F5 & $67.2 \pm 1.05$ & $53.12 \pm 0.32$ & $34.42 \pm 1.36$ & $54.8 \pm 1.35$ & $53.2 \pm 0.44$ \\
6 & F6 & $62.8 \pm 0.69$ & $70.1 \pm 0.83$ & $44.46 \pm 0.85$ & $45.3 \pm 0.56$ & $70.2 \pm 0.76$ \\
7 & F7 & $79.2 \pm 0.75$ & $68.9 \pm 0.23$ & $71.35 \pm 0.98$ & $48.5 \pm 0.68$ & $69.1 \pm 0.82$ \\
8 & F8 & $80.5 \pm 1.05$ & $71.4 \pm 0.91$ & $88.02 \pm 1.25$ & $39.2 \pm 0.85$ & $71.6 \pm 0.42$ \\
9 & F9 & $83.2 \pm 0.82$ & $84.4 \pm 1.05$ & $93.40 \pm 0.08$ & $29.6 \pm 0.93$ & $84.5 \pm 0.19$ \\
\hline
\end{tabular}

mean $\pm \mathrm{SD}, \mathrm{n}=3$.
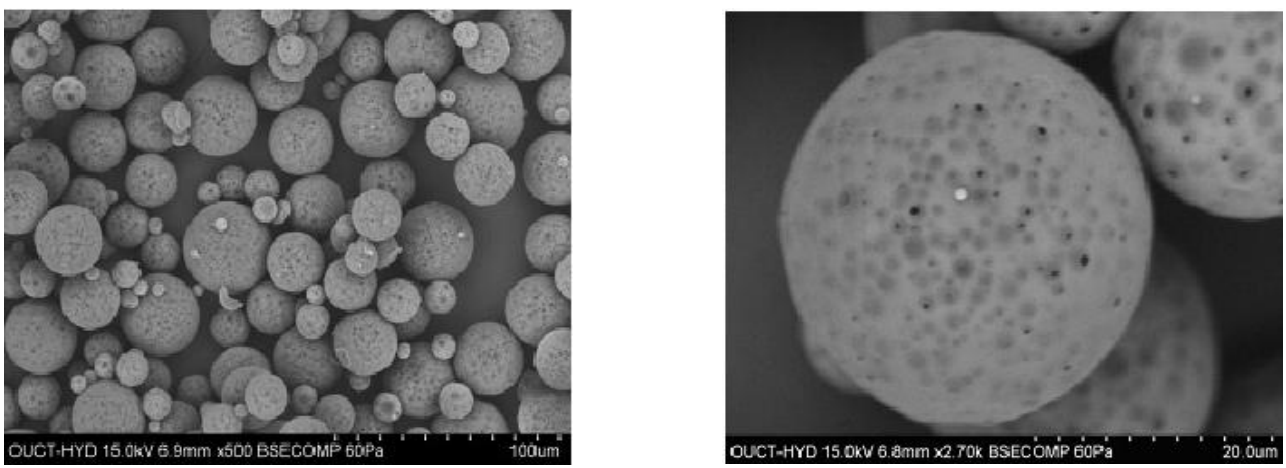

Fig. 4 \& 5: SEM images of Drug loaded microponges at 1000 rpm.
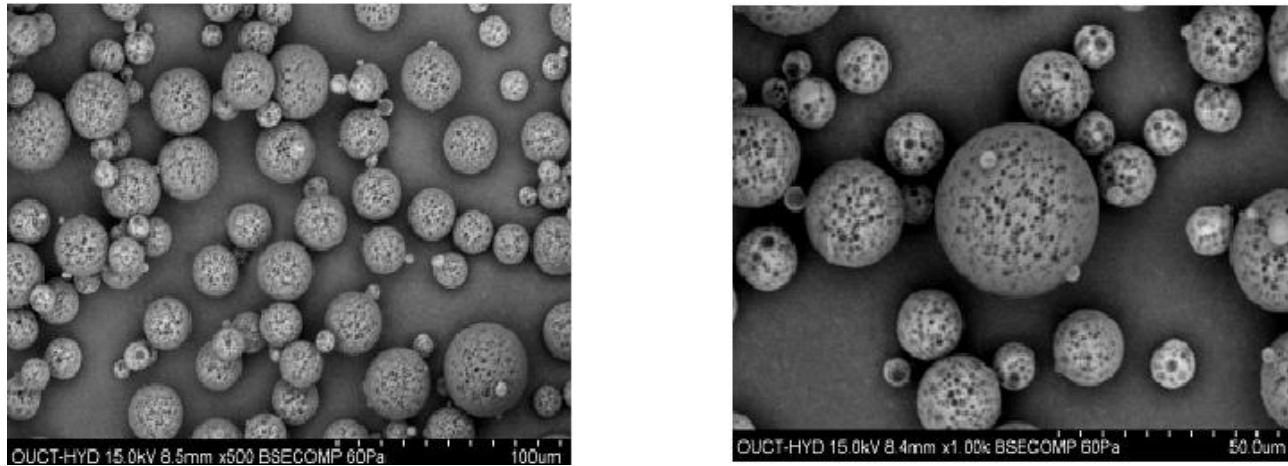

Fig. 6 \& 7: SEM images of Drug loaded microponges at $2000 \mathrm{rpm}$.

\section{Determination of loading efficiency (Percentage entrapment efficiency analysis)}

Precisely weighed quantity $(100 \mathrm{mg})$ of microsponges containing drug was kept in $100 \mathrm{ml}$ phosphate buffer solution $(\mathrm{pH}$ 6.8) for $12 \mathrm{~h}$ with continuous stirring 21. Filtered samples (using $0.45 \mathrm{~lm}$ membrane filter) were further analyzed at $248 \mathrm{~nm}$ next to blank using UV spectrophotometer (Pharmaspec 1700, Shimadzu, Japan). Estimation of entrapment efficiency for all batches were done (Malamataris and Avgerinos, 1990) using following expressions and values were given in Table 2.

Encapsulation Efficiency $=\left(\mathrm{M}_{\text {act }} / \mathrm{M}_{\text {the }}\right) \times 100$

\section{Scanning Electron Microscopy analysis}

The morphology and surface characteristics of the microsponges were studied using scanning electron microscopy
(SEM) (Anderson et al., 1994). All the samples were coated with gold palladium alloy under vaccum. Coated samples were then examined using LEO 430 SEM analyzer. The dried samples were placed on NEM TAPE adhesive paper and photographed and shown in figures 4-7.

\section{In Vitro Drug release Studies}

The microsponges, equivalent to a $100 \mathrm{mg}$ drug were subjected to In-vitro release studies (Devrim and Canefe, 2006) The in vitro release of valsartan from the microsponges was studied using USP Paddle Type II apparatus with a stirring rate of $50 \mathrm{rpm}$.

The temperature was maintained at $37 \pm 0.5^{\circ} \mathrm{C}$. Drug release was carried out in $900 \mathrm{ml}$ of phosphate buffer (pH 6.8). An aliquot of $5 \mathrm{ml}$ sample was collected over a period of $8 \mathrm{~h}$ and was assayed spectrophotometrically for the drug at $\lambda \max 248 \mathrm{~nm}$. 
Each time sample was withdrawn, a fresh buffer was added to keep the dissolution medium volume constant. The Percent drug release values were given in Table 3 . A kinetic treatment of the data was performed to determine the mechanism of the release of the drug was given in Table 4.The cumulative release profiles of the formulations were represented in figures 8-10

\section{RESULTS AND DISCUSSION}

\section{Physical appearance}

Microsponge particles which are fairly white were obtained by quasi-emulsion solvent diffusion method; with good flow properties than as compared with pure drug.

\section{FTIR studies}

FTIR of drug and excipients revealed that there was no interaction between the selected drug and polymers.

\section{Particle size}

Visual inspection results of all batches done using optical microscope for particle size discovered decreased particle size with increase in drug:polymer ratio. Optimized batch has been found with more percent of intact, uniform, spherical particles during optical microscopy. In quasi emulsion solvent diffusion method affinity between good solvent and drug is stronger than the affinity between good solvent and poor solvent. Drug solution in the good solvent formed emulsion droplets (quasi) upon pouring into the poor solvent and the organic phase then diffused out in to the external phase resulting in the formation of pores in the micron-sized particles, known as microsponges that have taken a spherical shape due to constant stirring (Pande et al., 2015). The particle size of valsartan microsponge formulation were given in Table no 2.The formulations with ethyl cellulose F1-F9 shows the average particle sizes of $83.2,79.3,65.2,61.6,54.8,45.3,48.5$, 39.2 and 29.6 respectively. It was found that particle size is decreased upon increasing the RPM.

Table 3: In-vitro Drug release Profile.

\begin{tabular}{|c|c|c|c|c|c|c|c|c|c|}
\hline \multirow{2}{*}{ S.No. } & \multirow{2}{*}{ Formulation code } & \multicolumn{8}{|c|}{$\%$ Drug release } \\
\hline & & 1hr & $2 \mathrm{hr}$ & $3 \mathrm{hr}$ & 4hr & $5 \mathrm{hr}$ & 6hr & $7 \mathrm{hr}$ & $8 \mathrm{hr}$ \\
\hline 1 & F1 & 0.3585 & 0.7171 & 1.6135 & 2.8685 & 5.0199 & 5.5577 & 9.6812 & 12.7290 \\
\hline 2 & $\mathrm{~F} 2$ & 0.8964 & 1.4342 & 1.9721 & 3.7649 & 7.7091 & 7.8884 & 15.418 & 23.665 \\
\hline 3 & $\mathrm{~F} 3$ & 1.7928 & 2.1513 & 3.4065 & 5.3784 & 9.8605 & 10.577 & 23.665 & 28.505 \\
\hline 4 & F4 & 2.3306 & 2.6892 & 3.944 & 6.8127 & 10.577 & 11.294 & 12.72 & 29.402 \\
\hline 5 & F5 & 5.199 & 6.274 & 8.0677 & 8.247 & 10.936 & 12.729 & 15.776 & 34.422 \\
\hline 6 & F6 & 7.709 & 9.681 & 10.936 & 12.191 & 12.37 & 15.418 & 23.84 & 44.46 \\
\hline 7 & F7 & 14.34 & 18.10 & 27.25 & 32.98 & 36.93 & 39.08 & 54.60 & 71.35 \\
\hline 8 & F8 & 16.314 & 27.60 & 34.42 & 38.007 & 54.14 & 58.26 & 73.68 & 88.02 \\
\hline 9 & F9 & 29.4 & 34.42 & 44.46 & 71.35 & 75.29 & 81.39 & 86.77 & 93.40 \\
\hline
\end{tabular}

Table 4 : Kinetic data from in vitro Drug release models for the microsponge formulations.

\begin{tabular}{|c|c|c|c|c|c|}
\hline S.No & $\begin{array}{c}\text { Formulation } \\
\text { code }\end{array}$ & $\begin{array}{c}\text { Zero order correlation } \\
\text { coefficient } \mathbf{R}^{2}\end{array}$ & $\begin{array}{c}\text { First order } \\
\text { correlation coefficient } \mathbf{R}^{2}\end{array}$ & $\begin{array}{c}\text { Higuchi correlation } \\
\text { coefficient } \mathbf{R}^{2}\end{array}$ & $\begin{array}{c}\text { Peppas plot Diffusional } \\
\text { exponent } n\end{array}$ \\
\hline 1 & F1 & 0.783 & 0.820 & 0.586 & 0.977 \\
\hline 2 & $\mathrm{~F} 2$ & 0.751 & 0.831 & 0.511 & 0.909 \\
\hline 3 & F3 & 0.833 & 0.849 & 0.545 & 0.879 \\
\hline 4 & F4 & 0.694 & 0.703 & 0.546 & 0.871 \\
\hline 5 & F5 & 0.741 & 0.882 & 0.576 & 0.751 \\
\hline 6 & F6 & 0.789 & 0.869 & 0.586 & 0.683 \\
\hline 7 & F7 & 0.845 & 0.853 & 0.842 & 0.934 \\
\hline 8 & F8 & 0.887 & 0.923 & 0.834 & 0.971 \\
\hline 9 & F9 & 0.880 & 0.958 & 0.724 & 0.939 \\
\hline
\end{tabular}

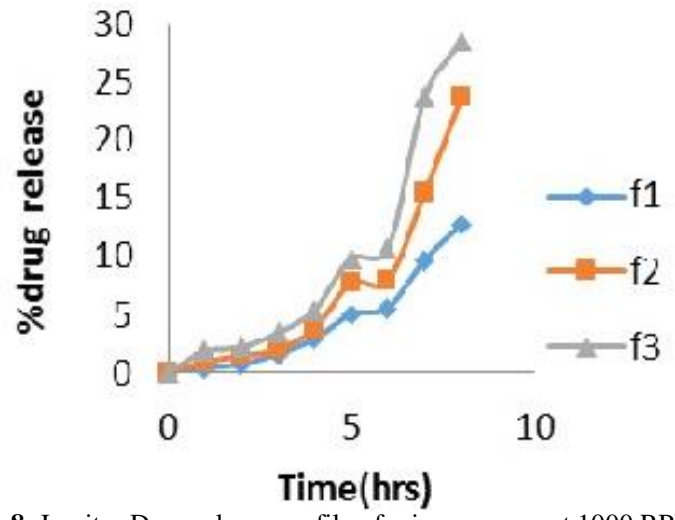

Fig. 8: In vitro Drug release profile of microsponges at 1000 RPM.

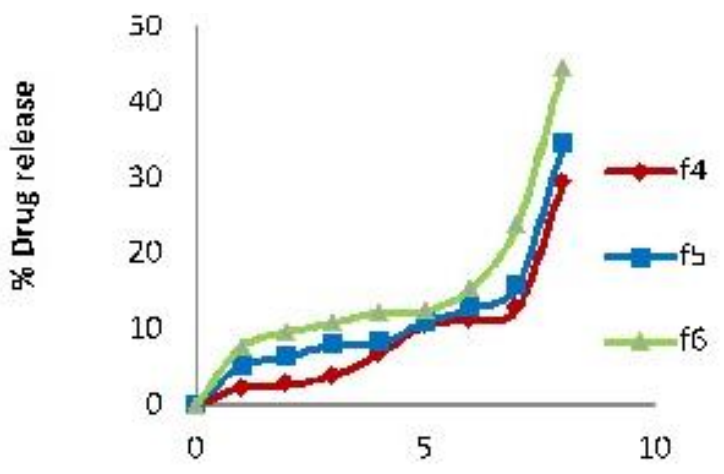

Time[hrs]

Fig. 9: In vitro Drug release profile of microsponges at 1500 RPM. 


\section{Scanning Electron Microscopy Analysis}

Scanning electron microscopy confirms the outer surface of M1 and M9 formulations was smooth and dense, while theshape of microsponges prepared by quasi-emulsion solvent diffusion method were spherical, and uniform with no drug crystals on surface. The higher the rate of stirring, the higher the early solvent drag for diffusion and accordingly the agglomeration of microsponge. It was hypothesized that with the increase in speed, the precipitation of polymer solution droplets gradually became slower, allowing more time for formation of agglomeration. Hence for batch F9 desired porous micro sponges with maximum entrapment of drug was observed.

\section{Drug content}

The drug content of valsartan microsponge formulation are given in Table 2. It was found the drug content increased with increase in the drug: polymer ratio as well as increase in rotation per minute. The drug content in formulations with ethyl cellulose from F1-F9 ranges between 33.7-84.4

\section{Production yield}

The production yield of valsartan microsponge formulation are given in Table 2.It was found that production yield increased with increase in the drug : polymer ratio. The formulations F1-F9 shows the production yield values of 51.3, $58.6,61.3,67.2,62.8,79.2,80.5$ and 83.2 respectively

\section{Entrapment efficiency}

The entrapment efficiency of valsartan microsponge formulation are given in Table 2.The Entrapement efficiency in formulations with ethyl cellulose from F1-F9 ranges between $33.8-84.5$

\section{Effect of drug to polymer ratio}

Production yield, drug content and entrapment efficiency was found to be increase with increase in drugpolymer ratio while drug:polymer ratio has reverse effect on particle size, as drug:polymer ratio increase, particle size decreases.

\section{Effect of stirring rate on the morphology and yield of microsponges}

The effect of stirring rate on the morphology of microsponges is shown in Fig 4-7. The formulation with higher drug to polymer ratio (i.e., 1:6) was chosen to investigate the effect of stirring rate on the morphology of microsponges. The stirring rate was varied in the range of 1000 to $2000 \mathrm{rpm}$. The dispersion of the drug and polymer into the aqueous phase was found to be dependent on the agitation speed. As the speed was increased the size of microsponges was reduced and the microsponges were found to be spherical and uniform. A decrease in particle size was observed with increases in the drug: polymer ratio, which could be correlated with the kinetics of microsponge formation in the presence of comparatively lower concentrations of the polymer (Niray Patel et al., 2016). When the rate of stirring was increased up to $2000 \mathrm{rpm}$ the spherical microsponges were formed with mean particle size of $29.6 \pm 0.86 \mu \mathrm{m}$. It was also noted that at higher stirring rate, the production yield was increased.

\section{Dissolution profile}

The dissolution rates are inversely related to particle size as would be expected from surface area relationships. The drug polymer ratio showed significant effect on the encapsulation efficiency of microsponges. The increased concentration of polymer showed the increased drug encapsulation efficiency. It was found that after $8 \mathrm{hrs}$ of dissolution study the formulations F1, F2, F3, F4, F5, F6, F7, F8 and F9 (figure 10) were showing 12.70, $23.66,28.50,29.40,34.42,44.46,71.35,88.02$ and $93.40 \%$ of drug release in $8 \mathrm{hrs}$. The study indicated that the amount of drug release is increased. Formulation F9 shows better result with 93.40 (\% drug release) than other formulations.

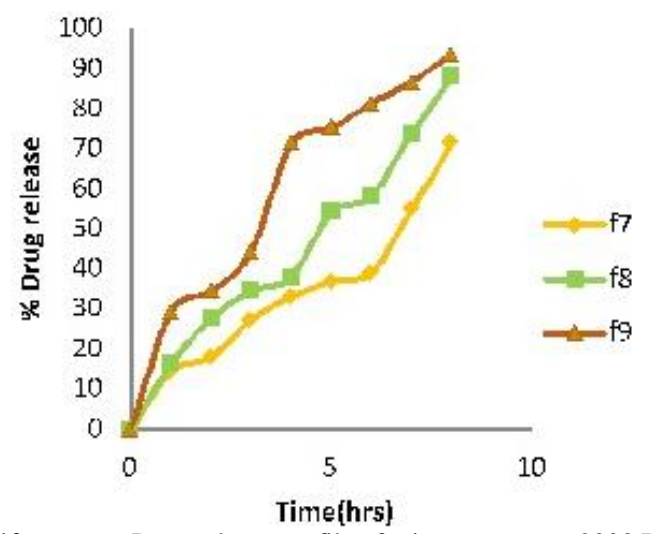

Fig. 10: In-vitro Drug release profile of microsponges at 2000 RPM

\section{Drug release kinetics}

The mechanism of drug release from the formulations during the dissolution was determined using the zero order, first order, higuchi equation and Peppas equation. All formulations were best fitted to Zero order and peppas plot. The best formulation follows Zero order and release mechanism is non fickian diffusion

\section{CONCLUSION}

Controlled drug delivery via the polymer based systems has been proposed to be prevailing both in present and in future; as having numerous potential advantages for scientific as well as economic reasons. The thought behind developing polymeric microsponge delivery system was to deliver active ingredient in a continual manner for extensive time period to reduce application frequency, hypersensitive reactions and to improve bioavailability, safety than marketed conventional formulation and precisely control the release rates or target drugs to a specific body site have a vast impact on the health care system. The method implemented was quasi-emulsion solvent diffusion; found to be simple, reproducible and rapid and was evaluated for its different parameters which revealed many interesting results for efficient preparation of the microsponges. The formulation F9 have better 
results than other formulations. FT-IR spectroscopy analyses indicated the chemically stable, amorphous nature of the drug in these microsponges. SEM photographs revealed the spherical nature of the micro sponges in all variations. Varied drug-polymer ratio and stirring rate reflected remarkable effect on particle size, drug content and encapsulation efficiency. It was observed that as the drug to polymer ratio was increased, the particle size decreased. This could probably be due to the fact that in high drug to polymer ratios, the amount of polymer available per microsponge was comparatively less. Hence fewer polymers surrounded the drug resulting in smaller microsponges. The effect of stirring rate on the morphology of microsponges was also investigated. The dispersion of the drug and polymer into the aqueous phase was found to be dependent on the agitation speed. As the speed was increased, the size of microsponges was reduced and uniform spherical microsponges were formed .It was also noted that at higher stirring rate, the production yield was decreased. Possibly at the higher stirring rates the polymer adhered to paddle due to the turbulence created within the external phase, and hence production yield increased. A microsponge delivery system can release its active ingredient on a timer mode. Therefore, micro sponge has got a lot of potential and is a very emerging field which is needed to be explored. Microsponges constitute a significant part by virtue of their small size and efficient carrier characteristics.

\section{ACKNOWLEDGEMENTS}

The authors thank Acharya Nagarjuna University College of Pharmaceutical Sciences, Guntur for providing all laboratory facilities, and for recording FT-IR Spectra, Osmania University, Hyderabad for Performing SEM analysis.

\section{Financial support and sponsorship: Nil.}

Conflict of Interests: There are no conflicts of interest.

\section{REFERENCES}

D'souzaJI.,Saboji JK., Killedar SG and More HN. Design and Evaluation of Benzoyl peroxide microsponges to enhance therapeutic efficacy in acne treatement. Accepted for presentation in 20th FAPA congress, Bangkok. 2004.

Jain N., Sharma PK., Banik A. Recent advances on microsponge delivery system. Int. J. Pharm. Sci. Res. 2011; 8(2) : 13-23.

Karthika.R., Elango.K., Ramesh Kumar K., Rahul.K. Formulation and evaluation of lornoxicammicrosponge tablets for the treatment of arthritis. Int. J. Pharmaceutical innovations. 2013; 3(2):29-40.

Mine O., ErdalC ., Ahmet A. Design and evaluation of colon specific drug delivery system containing flurbiprofen microsponges. Int. J. Pharm. 2006; 318, 103-117.

Mohan kumar V., Veena N M ., Manjula B P. Formulation and Evaluation of Meloxicam microsponges gel microsponges for topical drug delivery of mupirocin. Int. J. Pharm Tech Research. 2013; 5(3): 1434-1440.

Parikh BN., Gothi GD., Patel TD.,Chavda HV., Patel CN. Microsponge as novel topical drug delivery system. Journal of Global Pharma Technology. 2010; 2(1):17-29.

Partibhan KG., Manivannan R., Krishnarajan D., Chandra S., Nidhin R. Microsponges role in novel drug delivery. Int. J. of Pharm. Research and Devlopment.2011;3(4):117-125.
Saboji, J. K., Manvi, F. V., Gadad, A. P., Patel B. D. Formulation and evaluation of ketoconazole microsponge gel by quassi emulsion solvent diffusion. Journal of cell and tissue research. 2011; 11(1): 2691-2696.

Singh R., Jain V. Preparation and characterisation of dicyclomineloaded eudragit based microsponge with potential for colonic delivery. Topical J. Pharm. Research. 2010; 9(1): 67-72.

Vikas Jain, Ranjit Singh. Development and characterization of EudragitRs 100 loaded microsponges and Its colonic delivery using natural polysaccharides. Actapoloniaepharmaceutica-drug research. 2010; 67(4): 407 415.

V. Chadawar., J. Shaji. Microsponge delivery system. Curr. Drug Del. 2007; 123-129.

A.Nokhodchi., M. Jelveghari., M. R. Siahi ., S. Dastmalchi. The effect of formulation type on the release of benzoyl peroxide from microsponges, .Iranian J. Pharm. Sci. 2005; 131-142.

N. Amrutiya., A. Bajaj., M. Madan, Development of microsponge for topical delivery of mupirocin. AAPS PharmSciTech. 2009; 402-409.

Singh R., Jain V. Preparation and characterisation of Dicyclomineloaded Eudragit based microsponge with potential for colonic delivery. Topical J. Pharm. Research. 2010; 9(1): 67-72.

Orlu M., Cevher E., Araman A. Design and evaluation of colon specific drug delivery system containing flurbiprofenmicrosponges. Int J Pharm. 2006; 318: 103-117.

Subhash S., Vaghani SS., Jivani NP., Vasanti S., Satish CS., Patel MM. Preparation and characterization of 5- FU loaded microspheres of eudragit and ethylcellulose. Acta Pharm Sciencia .2010; 52: 391-9.

Mahajan AG., Jaytap LS., Chaudhari AL., Swami SP., Mali PR. Formulation and evaluation of microsponge drug delivery using indomethacin. Int Res J Pharm. 2011; 2(10):64-9.

R'e, M.I., Biscans, B. Preparation of microspheres ofketoprofen with acrylic polymers by a quasi-emulsion solvent diffusion method. Powder Technol. 1999;101: 120-133.

Bodmeier R., Chen H. Preparation and characterization of microspheres containing the anti-inflammatory agents, Indomethacin, Ibuprofen, andketoprofen. J Control Release.1989; 10:167-175.

N.H. Aloorkar, A.S. Kulkarni., D.J., Ingale R.A. Patil,Microsponges as Innovative Drug Delivery Systems. International Journal of Pharmaceutical Sciences and Nanotechnology, 2012; 5(1).

Malamataris S., Avgerinos A. Controlled release indomethacin microspheres prepared by using an emulsion solvent-diffusion technique. Int $\mathrm{J}$ Pharm. 1990; 62:105-11.

Jain V., Singh R. Design and characterization of colon-specific drug delivery system containing paracetamolmicrosponges. Arch. Pharm. Res. 2011; 34: 733-740.

Anderson D.L., Cheng C.H., Nacht S. Flow Characteristics of Loosely Compacted Macroporous Microsponge Polymeric Systems. Powder Technol. 1994; 78: 15-18.

Neelam Jain., Pramod Kumar Sharma., Arunabha Banik. Recent advances on microsponge delivery system. International Journal of Pharmaceutical Sciences Review and Research. 2011; 8(2).

Devrim B., CanefeK. Preparation and evaluation of modified release ibuprofen microspheres with acrylic polymers (Eudragit ${ }^{\circledR}$ ) by quasi emulsion solvent diffusion method: effect of variables. Acta Pol. Pharm.: Drug Res.2006; 63: 521-534

V. V. Pande., N. A. Kadnor., Rrupali N., Kadam., S. A. Upadhye. Fabrication and Characterisation of Sertaconazole nitrate Microsponge as a topical drug delivery system. Indian J Pharm Sci 2015; 77(6):675-680.

Niray Patel., Niya Tipadia., Neha Vadgama, Mihir Raval. Formulation and evaluation of microsponge gel for topical delivery of fluconazole for fungal therapy. Journal of Pharmaceutical Investigation 2016; 46(3).

\section{How to cite this article:}

Desavathu M, Pathuri R, Chunduru M. Design, Development and Characterisation of Valsartan Microsponges by Quasi Emulsion Technique and the Impact of Stirring Rate on Microsponge Formation. J App Pharm Sci, 2017; 7 (01): 193-198. 